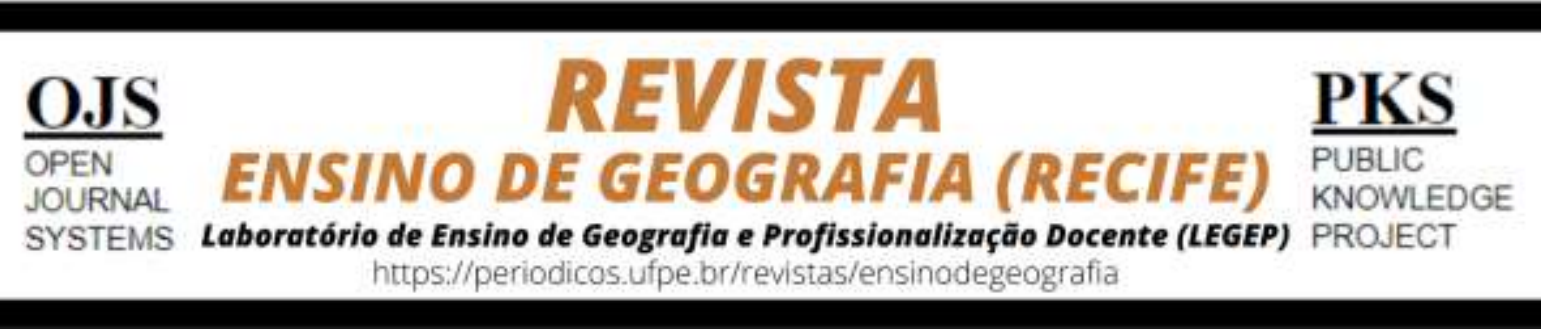

\title{
O CONHECIMENTO GEOGRÁFICO E AS HISTÓRIAS EM QUADRINHOS: UMA EXPERIÊNCIA DE ENSINO COM MAFALDA
}

\author{
Magnólia Oliveira Soares ${ }^{1}$, Marluce Silvino² \\ ${ }^{1}$ Especialista em Ensino de Geografia pela Universidade Estadual da Paraíba. Atua na área de Ensino de \\ Geografia. E-mail: marlucesilvino28@gmail.com - ORCID iD: http://orcid.org/0000-0003-3805-1463 \\ ${ }^{2}$ Doutoranda em Geografia pela Universidade Federal do Ceará, Mestre e Graduada em Geografia pela \\ Universidade Federal do Rio Grande do Norte. Atua nas áreas de Ensino de Geografia e Geografia Urbana. E- \\ mail: marlucesilvino28@gmail.com - ORCID iD: http://orcid.org/0000-0002-9627-8781
}

Artigo recebido em 14/08/2019 e aceito em 03/02/2020

\begin{abstract}
RESUMO
O presente trabalho discute de que modo o conhecimento geográfico é abordado nas tiras de Mafalda e sua utilização na educação básica. Partimos, assim, da premissa de que é possível realizar uma leitura espacial a medida que as tiras de Mafalda trazem narrativas que permitem uma reflexão da realidade, podendo servir como fonte de informação para a análise das práticas socioespaciais que caracterizam nossa sociedade. Propondo reflexões acerca do potencial desta representação cultural e na tentativa de se construir um conhecimento significativo a partir do uso dos quadrinhos da Mafalda, buscamos oferecer um recurso didático-pedagógico que possibilite ao educando crescer como sujeito crítico e ciente do espaço que o cerca. Em virtude de seu elevado senso crítico e da forma irônica com que abordam alguns temas pertinentes à Geografia, as tirinhas de Mafalda podem ser utilizadas enquanto recursos metodológicos na sala de aula. Com a possiblidade de se tornar um suporte teórico e conceitual para o entendimento das contradições inerentes ao sistema capitalista vigente, bem como o desenvolvimento do senso crítico e reflexivo dos discentes no processo de ensino e aprendizagem.
\end{abstract}

Palavras-Chave: Ensino de Geografia. Histórias em quadrinhos. Mafalda. Capitalismo.

\section{GEOGRAPHICAL KNOWLEDGE AND STORIES IN COMIC: A TEACHING EXPERIENCE WITH MAFALDA}

\begin{abstract}
This paper discusses how geographic knowledge is approached in Mafalda's strips and its use in basic education.Thus, we start from the premise that it is possible to perform a spatial reading, because the strips of Mafalda bring narratives that allow a possible reading of reality, and can serve as a source of information for the analysis of sociospatial practices that characterize our society. Proposing reflections on the potential of this cultural representation and in an attempt to build a significant knowledge from the use of Mafalda comics, we seek to offer a didactic-pedagogical resource that enables the educating to grow as a critical subject and aware of the space that surrounds him. Due to their high critical sense and the ironic way with which they address some topics pertinent to geography, Mafalda's comic strips can be used as methodological resources in the classroom. With the possibility of becoming a theoretical and conceptual support for the understanding of the contradictions inherent to the current capitalist system, as well as the development of the critical and reflective sense of the students in the teaching and learning process.
\end{abstract}

Keywords: Geography Teaching. Comics. Mafalda. Capitalism. 


\section{INTRODUÇÃO}

A leitura crítica da imagem é sugerida como uma aprendizagem emergente que se faz urgente e necessária para que o indivíduo possa enfrentar a avassaladora onda de informações que são postas em circulação pela mídia. As reflexões, os estudos e a pesquisa na Geografia têm considerado a imagem como um recurso didático de extrema importância para o ensino da disciplina, logo considera-se como representação primordial para a compreensão do espaço geográfico.

A linguagem dos quadrinhos pode ser encontrada em instrumentos avaliativos de processos seletivos em Universidades, no Exame Nacional do Ensino Médio (ENEM) e em diversos tipos de material educativo ou avaliativo. Alcançou maior legitimidade ao ser recomendada como uma opção de linguagem educativa nos Parâmetros Curriculares Nacionais (PCN), desde o ano de 1997. É importante destacar que a inclusão e a distribuição de obras nessa linguagem para as instituições públicas por meio do Programa Nacional de Biblioteca na Escola (PNBE), a partir do ano de 2008, contribuíram para o aumento no número de pesquisas sobre as histórias em quadrinhos.

Em virtude de seu elevado senso crítico e da forma irônica com que abordam alguns temas pertinentes à Geografia, as tirinhas de Mafalda podem ser utilizadas enquanto recursos metodológicos na sala de aula. Entender o espaço geográfico significa compreender o papel que essa ciência possui, no sentido de investigar a realidade tanto em seu aspecto social quanto em suas premissas naturais, com ênfase nas relações entre sociedade e natureza.

O ensino de Geografia com a utilização das histórias em quadrinhos - especialmente as tiras de Mafalda - é pensado para trabalhar com algo que, entre outras características, seja instigante, criativo, crítico, questionador, podendo com humor e aprofundamento científico servir a propósitos didático-pedagógicos nas aulas de Geografia.

Desse modo, o presente trabalho objetiva analisar como as tiras de Mafalda podem auxiliar no desenvolvimento escolar dos alunos, caracterizando-as como recurso didático e reconhecendo os aspectos favoráveis de sua utilização nas aulas. Sendo muito importante que o professor tenha suficiente familiaridade com o gênero textual narrativo que são as tirinhas, conhecendo os principais elementos da sua linguagem e os recursos que ela dispõe para a representação do imaginário; domine razoavelmente o processo de evolução das histórias em quadrinhos, seus principais representantes e características como meio de comunicação de massa. 
Objetivando ampliar o conhecimento na área da linguagem em quadrinhos e sua utilização como recurso didático nas aulas de geografia, foi realizada uma pesquisa bibliográfica que possibilitou a identificação, registro e análise das relações existentes entre as tiras de Mafalda e a possiblidade de se tornarem um suporte teórico e conceitual para o entendimento das contradições inerentes ao sistema capitalista vigente, bem como o desenvolvimento do senso crítico e reflexivo dos discentes no processo de ensino e aprendizagem. Ao dominar adequadamente todos esses elementos, qualquer professor estará apto a incorporar os quadrinhos de forma positiva em seu processo didático, dinamizando as suas aulas, ampliando a motivação dos seus alunos e conseguindo melhores resultados no processo de ensino e aprendizagem.

\section{O ENSINO DE GEOGRAFIA E AS DIFERENTES LINGUAGENS}

A linguagem é considerada um sistema de propagação de ideias e interesses e organização das relações humanas. É comum associar o termo linguagem simplesmente a forma oral usada para comunicação, porém, ela recebe novas características no meio educacional junto aos recursos em questão. O ensino de Geografia deve ser trabalhado pelo professor por meio da utilização de diferentes linguagens que favoreçam aos alunos, produzir e expressar ideias, opiniões, sentimentos e conhecimentos sobre o espaço.

Mas, como despertar um olhar geográfico nos alunos? Selbach (2010) discorre sobre vários caminhos para motivar os alunos a conhecer destes procedimentos. O professor de Geografia deve: propor perguntas intrigantes, verdadeiros desafios a curiosidade e a inteligência de seus alunos; ajudá-los a associarem os temas que aprendem à própria vida e aos caminhos por onde caminham. Todo desafio de difícil alcance acaba por se tornar desinteressante para o aluno e, dessa forma, cabe ao professor propor perguntas de respostas possíveis, pesquisas de alcance viável, proposições compatíveis com soluções que possam ser encontradas. Como podemos observar nos questionamentos de Selbach (2010, p. 29):

\footnotetext{
Não será interessante para o aluno se não corresponder a satisfação de uma necessidade. Qual geografia ensinar? A geografia de La Blache marcadamente positivista, ou a geografia de Humboldt, desenhada pelo naturalismo? A geografia tradicional bem descritiva, levemente analítica e nada crítica, ou a geografia marxista, que clamava pela exclusividade da crítica e que só propunha problemas? A geografia fenomenológica, que se diz humanista, ou a geografia da percepção? Trata-se da geografia da abordagem teórica e metodológica; que não abre mão de fazer de nossos alunos atores autênticos na construção de paisagens e lugares e na certeza de que sua disciplina é fruto da interação entre o trabalho social e a natureza que ensina pessoas a pensar. Portanto, devemos ensinar é a geografia do bom senso.
} 
Ensinar uma Geografia que desperte um olhar crítico e reflexivo nos alunos, que os motivem a fazer uma leitura de mundo, que os façam conhecer o espaço geográfico em que vivem e avaliar seu processo de desenvolvimento e suas contradições recorrentes no tempo e no espaço. E para isso, é de suma importância a utilização de linguagens que propiciam uma leitura espacial usufruindo dos quadrinhos. É interessante observar as contribuições das perspectivas geográficas no decorrer do processo histórico de formação do pensamento geográfico.

A Geografia, entre outros motivos, deve ser ensinada por se tratar de uma ciência de paisagens e porque desperta a visão interligada entre o homem e seu mundo. É um instrumento que permite nos conhecer e nos compreender melhor, além de perceber toda a dimensão do espaço e do tempo, onde estamos e para aonde caminhamos, descobrir as populações e suas múltiplas relações com o ambiente. A leitura da paisagem permite verificar as suas diferenças, transformações e interações, e, principalmente a ação antrópica nas paisagens.

Recursos didáticos visam permitir a cada aluno, dentro do seu limite e respeitando seu nível de compreensão, interpretar, analisar e relacionar a importância das muitas linguagens no exame e leitura da paisagem e assim perceber a Geografia nas imagens, na literatura, nas notícias e em documentos de diferentes fontes. A linguagem não existe sem pensamentos, sem nada, e, por esse motivo, é muito importante conhecer quais são as "linguagens" da Geografia, pois é através delas que se expressam os conhecimentos geográficos. E utilizar essas linguagens aproveitando os diferentes signos, iconografias e gráficos para facilitar a leitura e compreensão das paisagens.

Callai (2011) afirma que a escola deve ser compreendida como o lugar de valorização da interpretação e da compreensão das novas linguagens e manifestações, sem perder o rumo da busca sempre ancorado na razão. A educação é mais complexa e, cada vez mais constatamos o papel, quase decisivo, da comunicação. O estudo da linguagem e da comunicação é indispensável para a compreensão do multidimensionalismo, e mais ainda a educação geográfica.

Constatamos que a principal contribuição dos quadrinhos para o ensino de Geografia não se resume a mera descrição das paisagens. O potencial dessa linguagem ultrapassa esse aspecto, podendo atender às mais recentes abordagens teóricas e pedagógicas da área conforme nos aponta Rondine e Torres (2014, p.6): “As diversas linguagens alternativas que podem ser utilizadas no ensino de Geografia objetivam tornar as aulas mais atrativas e significativas, o que leva a uma maior eficiência no processo de ensino aprendizagem”. 
Vivemos uma inusitada aceleração do processo de criações tecnológicas, fazendo com que técnicas e equipamentos considerados inovadores estejam em pouco tempo, obsoletos, tornando necessária uma constante renovação e atualização de técnicas. Do mesmo modo, as formas de ensino-aprendizagem sofrem modificações. Como destaca Silva (2010, p. 34),

É impossível para os professores ignorar a sobrecarga dos avanços das técnicas e formas de comunicação diária na vida das pessoas. Ao contrário, necessitam aproveitar o impacto dessas inovações e se empenharem na função de questionar, buscando despertar o senso crítico dos estudantes, para que estes tenham condições de avaliar com um olhar seletivo e de se apropriarem das informações com uma visão mais coerente do mundo atual.

As diferentes linguagens precisam estar presentes na didática escolar, os docentes não podem ignorar os avanços das técnicas e formas de comunicação. Ao contrário, necessitam aproveitar o impacto dessas inovações e se empenharem na função de questionar, buscando despertar o sentido crítico dos discentes, para que estes tenham condições de avaliar - com um olhar seletivo - e se apropriar das informações com uma visão mais coerente do mundo atual.

É preciso compreender para utilizar adequadamente outras linguagens na escola. Em consonância com essa argumentação, Silva (2010) reconhece que as tecnologias fazem parte da vida do ser humano, os professores devem aprender a usá-las para aprimorar e melhorar a qualidade do ensino-aprendizagem dos estudantes. A possibilidade dessa utilização promove outras estratégias de ensino-aprendizagem, injeta mais dinamismo nas aulas e intensifica a construção de conhecimento.

Sabemos que apenas a utilização dos livros didáticos, muitas vezes, não é suficiente para aulas criativas, prazerosas e com a efetiva participação do aluno. Faz-se necessário buscar metodologias diversificadas para uma melhor apropriação do conhecimento pelos alunos, porém, ter domínio da técnica é tão importante quanto possuir o domínio do conteúdo, das formas de avaliação e do uso dos recursos.

Considerando que a Geografia é uma disciplina que permite aos discentes observar, analisar e comparar, deve então buscar ferramentas que possam colaborar na compreensão dos conteúdos estudados, despertando a sensibilidade para um olhar crítico sobre o espaço, e não apenas uma visualização.

Desponta no contexto histórico atual, a necessidade do uso de novas tecnologias como ferramentas para superar desafios postos concernentes ao ensino e aprendizagem, como a utilização de histórias em quadrinhos, pois a interligação do texto com a imagem amplia a 
compreensão de conceitos e o seu caráter elíptico proporciona ao leitor o pensar e o imaginar. Para Rahd (1996, p. 12):

\begin{abstract}
A história em quadrinhos começou a ultrapassar o espaço do divertimento de massa para, a partir daí, influenciar os leitores em esferas psicológicas e sociais, porque era uma forma de leitura alternativa. Nascia uma literatura de comunicação visual da cultura de massa. Estudos e avaliações da história em quadrinhos indicaram que o novo meio, que então surgia, possuía e ainda possui um efeito positivo para a educação da leitura e da cultura da imagem.
\end{abstract}

Desse modo a leitura geográfica se torna possível também por meio desta linguagem a medida que se estrutura pela análise num determinado tempo e espaço de um acontecimento, a se caracteriza como forma de leitura própria, constituído por textos e imagens, expressões que auxiliam na construção de conhecimentos a partir daquilo que é vivido pelos indivíduos, sobre isso Neves e Rubira ( 2017, p. 121) constatam "Dialogando com a Geografia, as histórias em quadrinhos podem ser apresentadas diante de grande e vasto conteúdo, que é inerente a ela".

É imprescindível para o saber geográfico o uso das imagens que são representações do real, e gestora no imaginário dos conceitos; lugar, paisagens e demais categorias. Os quadrinhos revelam-se como reprodução fictícia como aponta Rama (2006, p. 11).

Cabe ressaltar, portanto, que as histórias em quadrinhos, por mais que se apresentem calcadas na ficção, acabam por possibilitar uma visão da sociedade na qual são criadas, podendo servir como fonte de informação para análise das práticas socioespaciais que caracterizam essa mesma sociedade.

Mas são ficções que buscam reproduzir a realidade, no caso das tiras de Mafalda que abordaremos a diante o autor foca em questões políticas/econômicas de modo a fazer o leitor refletir de maneira crítica sobre o cenário atual muitas vezes de forma cômica, porém estruturada pela problemática do espaço vivenciado. Nesse sentido as tirinhas que são feitas embora muitas vezes para leitores diversos se sobressai como possibilidade de uso no ensino a medida que possibilita aos discentes pensar e repensar sua existência e seu papel no contexto em que se insere.

\title{
AS TIRAS DE MAFALdA PARA MEDIAR A FORMAÇÃO DE CONCEITOS GEOGRÁFICOS
}

Analisando as tiras de Mafalda percebemos a possibilidade de fazermos uma leitura do espaço, levando em consideração a importância dessa forma de linguagem e desses ícones no mundo moderno. Algumas de suas tirinhas fazem referência a diversos temas geográficos, ao 
estudo dos mapas, representações, relações sociais, política, democracia, dentre outros, o que as transformam em um bom instrumento didático a ser trabalhado, servindo para introduzir e dinamizar as aulas de geografia.

Em 1969, o primeiro livro de Mafalda publicado fora das fronteiras da Argentina é feito na Itália e editado por Umberto Eco. Por fim, em 25 de junho de 1973, a última tira de Mafalda foi publicada por decisão do próprio Quino. As tiras foram publicadas até 1973. Naquele ano, Quino percebeu que em Mafalda não teria como comentar os assuntos mais recentes, pois as tirinhas deveriam ser entregues semanas antes da publicação. Decidiu parar com o trabalho. Desde então, novos trabalhos com Mafalda foram apresentados, mas apenas para campanhas publicitárias, como as da UNICEF (COELHO, 2017).

Filho de imigrantes espanhóis de Andaluzia, Joaquim Salvador, ou apenas Quino, nasceu em 1932 na província de Mendoza na Argentina. A paixão pelo desenho foi despertada logo cedo, por um tio de mesmo nome, ilustrador. Aos 17 anos, após a morte do pai, Quino abandonou os estudos na escola de belas artes de Mendoza com o sonho de ser escritor de histórias em quadrinhos.

Em 1954, mudou-se para Buenos Aires, mas seu reconhecimento não foi imediato pois nenhuma editora o aceitou, ainda que já tivesse vendido uma de suas histórias. Mais tarde, com a publicação de Mafalda, Quino se destacaria pelo humor ácido e cínico, implacável na crítica da condição humana.

Aos poucos, o universo de Mafalda tornou-se mais abrangente. Quino criou um microcosmo representativo do contraste de valores da época, incluindo novos personagens as suas historietas, dentre os quais merecem destaque: Susanita, Susana Clotilde (ou Susana Beatriz), criada em 6 de julho de 1965, representa a mulher burguesa que almeja a tranquilidade de uma família construída, filhos para criar e amigas com quem passar horas de enfado. Sempre fora da realidade, busca não se envolver com os problemas do mundo e vive presa a aparências (COELHO, 2017). 
Figura 01- Susanita

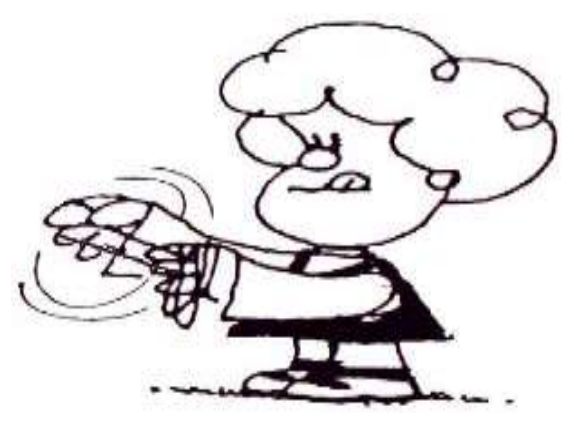

Fonte: blog El Pais acesso em 2018. ${ }^{1}$

Enquanto Mafalda personifica a mulher livre que busca igualdade em relação ao sexo oposto, Susanita representa a visão tradicional da mulher tradicional, o que ocasiona frequente atrito entre as duas garotas. Filipe, criado em 19 de janeiro de 1965, é um sonhador que odeia a escola, mas que trava intensas batalhas com sua consciência e seu senso nato de responsabilidade. Apesar de estar mais avançado que Mafalda na escola, vê a vida de forma mais simples e de acordo com sua idade. Foi inspirado no jornalista Jorge Timossi, amigo de Quino. Manolito, por sua vez, foi criado em 29 de março de 1965, é filho de um comerciante e representa as ideias conservadoras e capitalistas dentro da história (COELHO, 2017).

Figura 02 - Manolito

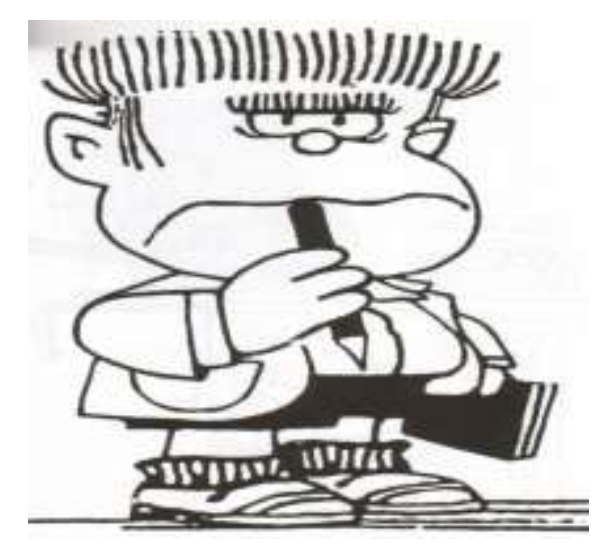

Fonte: blog Jegutierrezo acesso em $2018 .^{2}$

\footnotetext{
${ }^{1}$ Disponível em: <http://blogs.elpais.com/la-novia-de-papa/2011/01/soy-tu-mejor-amiga.html> Acesso em: 19 mar. 2018.

${ }^{2}$ Disponível em: <https://jegutierrezo.wordpress.com/>. Acesso em: 19 mar. 2018.
} 
Figura 03 - Filipe

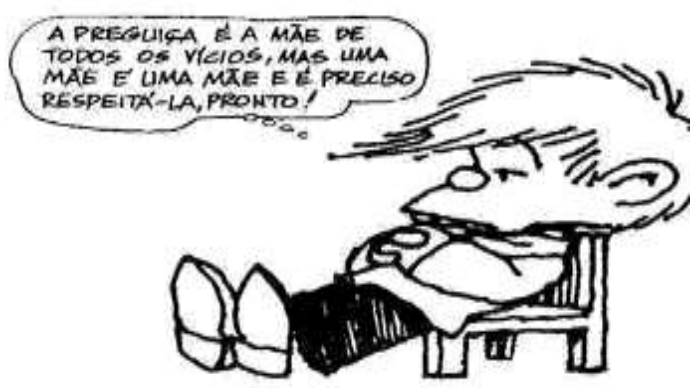

Fonte: Site explore frases engraçadas, palavras soltas e muito mais acesso em $2018^{3}$

Manolito é ambicioso e materialista, não gosta dos Beatles. Tira notas baixas em todas as matérias, menos em matemática, por causa das contas que aprende no mercado com o pai. Guille ou "Gui", criado em 1968, é o irmão caçula de Mafalda. Esperto para a sua idade, é retratado como uma criança que começa a perceber o mundo. Miguel "Miguelito", criado em 1966, é mais sonhador que Filipe e costuma fazer perguntas absurdas sobre a realidade. Transita entre reflexões etéreas e típicas queixas de criança, do gênero "sempre eu, sempre eu". Ele é filho único e também o mais inocente da trupe. Libertad, a última personagem a unir-se à turma, criada em 15 de fevereiro de 1970, é uma menina baixinha, chegando a ser menor que Guille.

Figura 04 - Guille

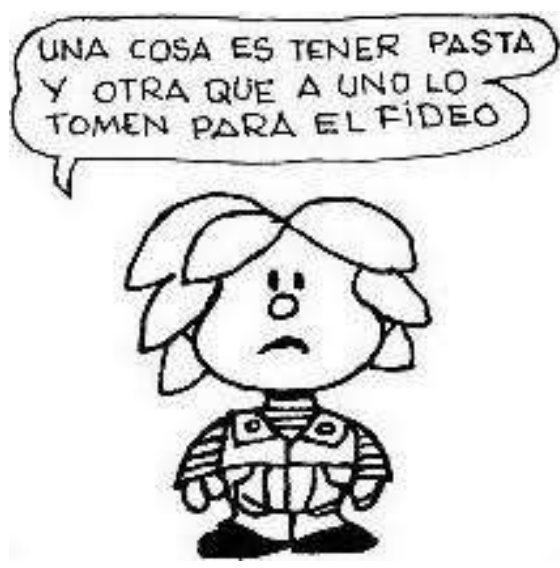

Fonte: Gustavo acesso em $2018 .^{4}$

\footnotetext{
${ }^{3}$ Disponível em: <https://br.pinterest.com/pin/473933560772377813/.> Acesso em: 19 mar. 2018.

${ }^{4}$ Disponível em: <https://twitter.com/gmodica82.>. Acesso em: 19 mar. 2018.
} 
Ao contrário dos outros amigos de Mafalda, quase sempre conservadores, Libertad também é bastante liberal e fala sobre como o povo precisa ter consciência da situação do país, organizar uma revolução social e reestruturar a Argentina. Entre as crianças, é a que mais conversa com Mafalda sobre política. A diferença entre as duas é que Mafalda é menos de esquerda que a amiga. Libertad deseja ser tradutora de francês, como a mãe (COELHO, 2017).

Figura 05 - Libertad

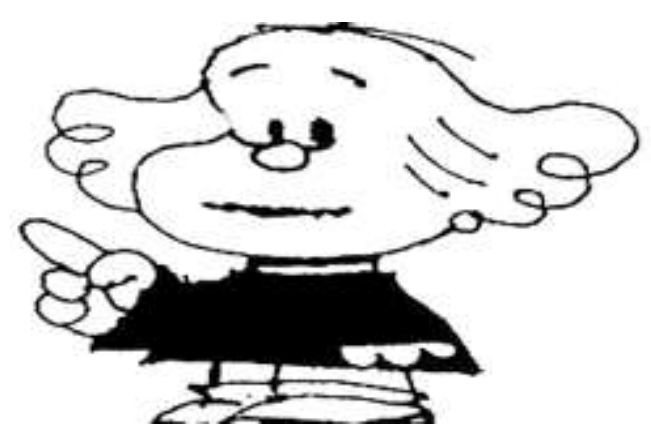

Fonte: Imagem salva do Google Chrome, acesso em $2018^{5}$

As tiras de Mafalda apresentam uma visão límpida da sociedade argentina da época em que foram criadas, questionando o status quo por meio dos olhos de uma menina de seis anos, sem soberba, que adora os Beatles e odeia sopa, além de ser crítica ferrenha de valores quase patriarcais, colonialistas e anti-povo da elite de seu país. No entanto, o que levou Mafalda a sobreviver ao tempo não foi seu discurso político, mas sim seu caráter humano, por mostrar sentimentos e questões sociais ainda presentes no âmago das pessoas e que demandam reflexão, o que na visão de seu criador - que se autodenomina um pessimista - deveria ser motivo de angústia e não de celebração.

Enquanto alguns quadrinhistas se distinguem pela sofisticação do traço, Quino tomou a via oposta. Segundo a jornalista Núbia Silveira

o traço simples, leve, limpo e expressivo do cartunista transforma em obra de arte cada quadro de uma tira. Os pequenos detalhes compõem as historietas que nos fazem sorrir e pensar. Os temas são cotidianos: as guerras mundiais, o engarrafamento no trânsito, o alto custo de vida, as férias na praia, o aprendizado escolar. A riqueza de Mafalda, com certeza, está nas ideias expostas. Não por acaso, Quino é citado em suas biografias como cartunista, desenhista e pensador (SILVEIRA apud COELHO, 2017, p. 22).

\footnotetext{
${ }^{5}$ Disponível em: <http://www.claridadpuertorico.com/images/articles/mafalda-libertad_xlg.jpg.> Acesso em: 19 mar. 2018.
} 
Em virtude de seu elevado senso crítico e da forma irônica com que abordam alguns temas pertinentes à atualidade, os conflitos sociais, econômicos e políticos, as tirinhas de Mafalda podem ser utilizadas em sala de aula na disciplina de Geografia. Muitas de suas tirinhas fazem referência ao uso dos mapas como instrumento ideológico, o que as transformam num instrumento didático a ser trabalhado para introduzir e dinamizar os conteúdos de cartografia e geopolítica, dentre outras áreas.

Entender o espaço geográfico significa também compreender as relações entre sociedade e natureza. $\mathrm{O}$ aluno de Geografia deve ser capaz de entender as implicações dessa relação de modo crítico. E nesse contexto, as tiras de Mafalda proporcionam essa análise, visto que possibilitam um olhar aguçado e reflexivo sobre o espaço contraditório, resultado de uma sociedade desigual.

O ensino de Geografia com a mediação de quadrinhos, especialmente com as tiras de Mafalda, é pensado para trabalhar com algo que, entre outras características, seja instigante, criativo, crítico, questionador, podendo com humor e aprofundamento científico servir a propósitos didático-pedagógicos.

Mediante as afirmativas de Vergueiro (2015) existem vários motivos que levam as histórias em quadrinhos a terem um bom desempenho nas escolas, possibilitando resultados muito melhores do que aqueles que se obteria sem elas. Há várias décadas, as histórias em quadrinhos fazem parte do cotidiano de crianças e jovens, sua leitura sendo muito popular entre eles. Contudo, a introdução das HQS na sala de aula não é objeto de rejeição por parte dos discentes, que em geral, as recebem de forma entusiasmada. Enfatizando a sua importância o autor disserta:

\footnotetext{
As histórias em quadrinhos aumentam a motivação dos estudantes para o conteúdo das aulas, aguçando sua curiosidade e desafiando seu senso crítico. A forte identificação dos estudantes com os ícones da cultura de massa - entre os quais se destacam vários personagens dos quadrinhos -, é também um elemento que reforça a utilização das histórias em quadrinhos no processo didático (VERGUEIRO, 2015, p. 21).
}

As possibilidades de comunicação são enriquecidas pela familiaridade com as HQs devido aos variados recursos da linguagem quadrinhística como o balão, a onomatopeia, os diversos planos utilizados pelos desenhistas. E auxiliam no hábito da leitura enriquecendo o vocabulário dos estudantes. As histórias em quadrinhos são escritas em linguagem de fácil 
entendimento, com muitas expressões que fazem parte do cotidiano dos leitores, porém, na medida em que tratam de assuntos variados introduzem sempre palavras novas aos estudantes e o vocabulário dos mesmos vai se ampliando.

O caráter elíptico ${ }^{6}$ da linguagem quadrinhística leva o leitor a pensar e imaginar, sendo uma narrativa com linguagem fixa. A constituição de uma história em quadrinhos implica na seleção de momentos chave da história para a utilização expressa na narrativa gráfica, deixando outros momentos a cargo da imaginação do leitor. Elipse é uma figura de linguagem da língua portuguesa, que consiste na omissão de um ou mais termos de uma oração, sendo que estes são facilmente identificados a partir do contexto do texto.

Por serem veiculados no mundo inteiro, os quadrinhos possuem uma abrangência global, pois trazem temáticas que podem ser compreendidas por estudantes de qualquer lugar, sem necessidade de um conhecimento anterior específico ou familiaridade com o tema, seja ela devida a antecedentes culturais, étnicos, linguísticos ou sociais.

As histórias em quadrinhos possibilitam através de seu uso a integração entre as diferentes áreas do conhecimento, oferecendo na escola um trabalho interdisciplinar e com diferentes habilidades interpretativas. Os quadrinhos podem ser utilizados em qualquer nível escolar e com qualquer tema, não existe barreira para o aproveitamento das histórias em quadrinhos nos anos escolares iniciais e para sua utilização em séries mais avançadas, mesmo em nível universitário.

Outras características que podem ser mencionadas concernentes ao uso das histórias em quadrinhos em ambiente escolar é a acessibilidade e o baixo custo quando comparadas com outros produtos da indústria cultural. Vergueiro (2015) sugere que as HQs sejam utilizadas na sequência normal das atividades e sem qualquer destaque em relação a outras linguagens ou alternativas didáticas.

$\mathrm{Na}$ utilização de quadrinhos no ensino é muito importante que o professor tenha suficiente familiaridade com o meio, conhecendo os principais elementos da sua linguagem e os recursos que ela dispõe para a representação do imaginário; domine razoavelmente o processo de evolução das histórias dos quadrinhos, seus principais representantes e características como meio de comunicação de massa. Ao dominar adequadamente todos esses elementos, qualquer professor estará apto a incorporar os quadrinhos de forma positiva em seu

\footnotetext{
${ }^{6}$ Expressão elíptica: Em que existe elipse numa figura de linguagem, omissão de uma ou várias palavras que não prejudicam o sentido da frase.
} 
processo didático, dinamizando suas aulas, ampliando a motivação dos seus alunos e conseguindo melhores resultados no processo de ensino e aprendizagem (VERGUEIRO, 2015).

A leitura crítica da imagem é sugerida como uma aprendizagem emergente que se faz urgente e necessária para que o indivíduo possa enfrentar a avassaladora onda de informações que são postas em circulação pela mídia. As reflexões, os estudos e a pesquisa na Geografia têm considerado a imagem um recurso didático de extrema importância para o ensino da disciplina, por entendê-la como representação primordial para a compreensão do espaço geográfico.

Dessa maneira, as linguagens dos quadrinhos podem ser empregadas na mediação do ensino de Geografia, pois:

\begin{abstract}
Os quadrinhos motivam a discussão e a reflexão e, principalmente, estimulam uma leitura mais apurada da realidade vivida e a desmistificação do discurso ideológico que permeia as relações sociais e políticas do mundo. Além disso, a linguagem desse produto cultural é capaz de fazer a aula mais agradável para muitos alunos, tornandoos mais receptivos ao conteúdo, uma vez que apreciam esse tipo de atividade, por promover debates polifônicos, estimular a perspicácia e o pensamento crítico. (SILVA, 2010, p.13).
\end{abstract}

Nessa discussão entra Mafalda. Ela é uma menina observadora e muito perspicaz do que se passa no mundo, sendo uma crítica implacável da sociedade. Uma análise crítica e reflexiva das tiras de Mafalda proporciona um maior entendimento das formações e transformações que ocorrem no espaço geográfico ao longo da história, e podem ser pontos de partida para se trabalhar temáticas inerentes aos conteúdos geográficos. É perceptível a abordagem recorrente do capitalismo e suas diversas facetas em muitas das tiras. Como nos mostra a figura 06, logo abaixo. 
Figura 06 - Desigualdade social
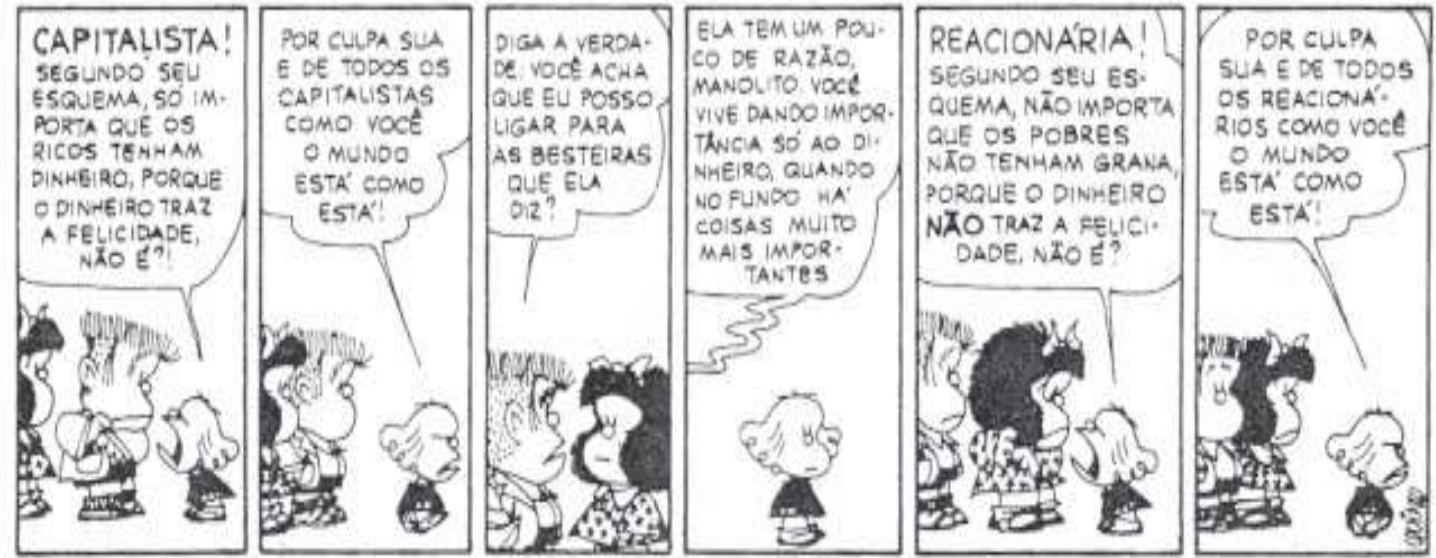

Fonte: Imagem salva do Google Chrome, acesso em $2018 .^{7}$

A tirinha da figura 06 mostra Libertad revoltada com as desigualdades sociais geradas com o avanço do capitalismo, concernentes a acumulação de riquezas e a concentração de renda. A tirinha nos permite uma contextualização, entendimento e melhor compreensão do sistema político econômico com o qual estamos inseridos e o seu papel na produção e reprodução socioespacial.

Figura 07 - Propriedade privada
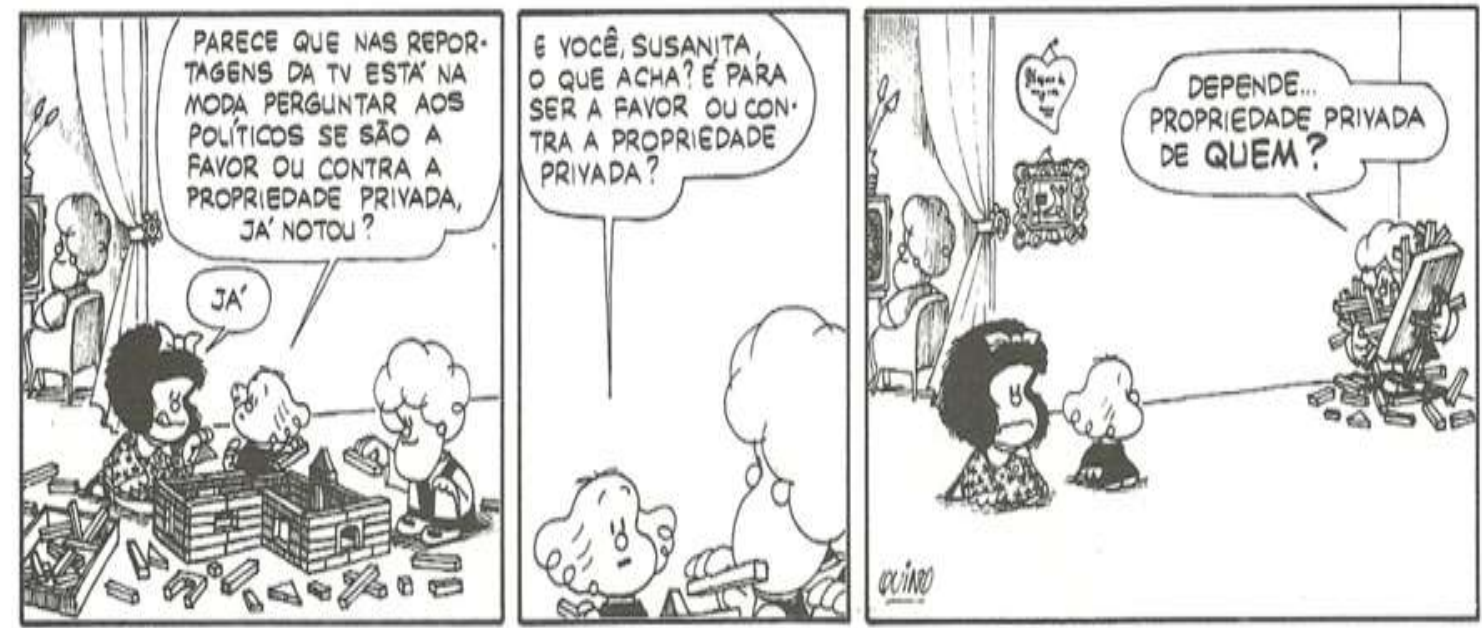

Fonte: Imagem salva do Google Chrome, acesso em 2018. ${ }^{8}$

\footnotetext{
${ }^{7}$ Disponível em: <http://i84.servimg.com/u/f84/13/54/27/90/mafald12.png> Acesso em: 19 mar. 2018.

${ }^{8}$ Disponível em: <https://capitalismoemdesencanto.files.wordpress.com/2014/01/tira.jpg>. Acesso em: 19 mar. 2018.
} 
Mais uma vez o questionamento é feito por Libertad, perguntando a Mafalda e a Suzanita se elas são a favor ou contra a propriedade privada. A propriedade privada faz parte do capitalismo, e também exerce uma função social.

Mafalda - uma personagem criança que não foi produzida pensando no público infantil - dialoga com diferentes faixas etárias. A partir dela é possível, por exemplo, tanto debater a democracia grega com o sexto ano como problematizar o conceito de alienação, a partir da mídia e do consumo, com uma turma de graduação em Pedagogia. Percebe-se que, se houver um levantamento prévio de suas várias possibilidades de uso, no ensino de Geografia, poderia ser mais apropriado na prática pedagógica. A adequada utilização desses materiais, aliada a uma proposta de estudo consistente e bem fundamentada, proporciona uma aprendizagem com maior senso crítico, reforçada pelo potencial educativo desses recursos, Silva e Cavalcanti (2008).

Figura 08 - Neoliberalismo
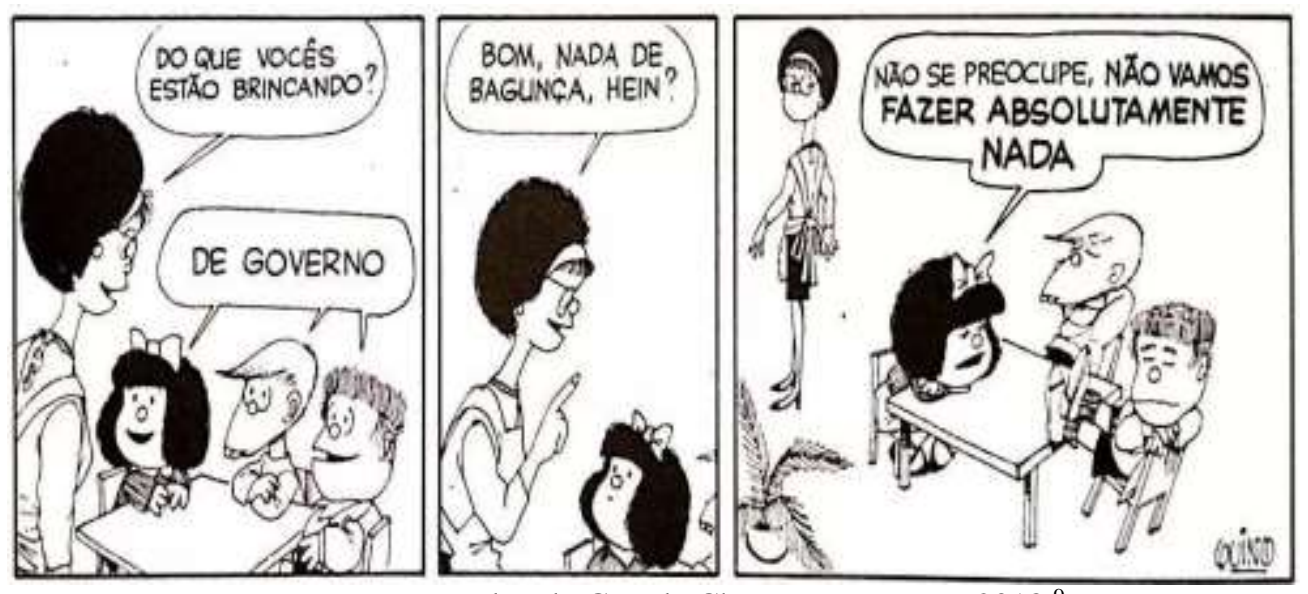

Fonte: Imagem salva do Google Chrome, acesso em 2018. ${ }^{9}$

A tirinha da figura 08 remete a uma característica muito importante da fase atual do capitalismo, que consiste na política neoliberal. O neoliberalismo é um processo que abrange aspectos econômicos, políticos, culturais, ambientais. Promove significativas mudanças no espaço, através das atividades humanas. Mafalda de uma forma simples, engraçada e contundente define essa política. Sendo possível uma análise da tirinha para abordar conceitos socioeconômicos e identificar as principais causas e consequências das mudanças que ocorrem no mundo com o fim da Guerra Fria, expansão do Capitalismo e a Globalização. Temas pertinentes ao ensino geográfico, logo mostram fenômenos responsáveis pela produção e reprodução socioespacial.

\footnotetext{
9 Disponível em: <https://meumundocommafalda.files.wordpress.com/2013/03/mafalda_0030.jpg? $\mathrm{w}=1271 \& \mathrm{~h}=363>$. Acesso em: 19 mar. 2018.
} 
Figura 09 - Consumo
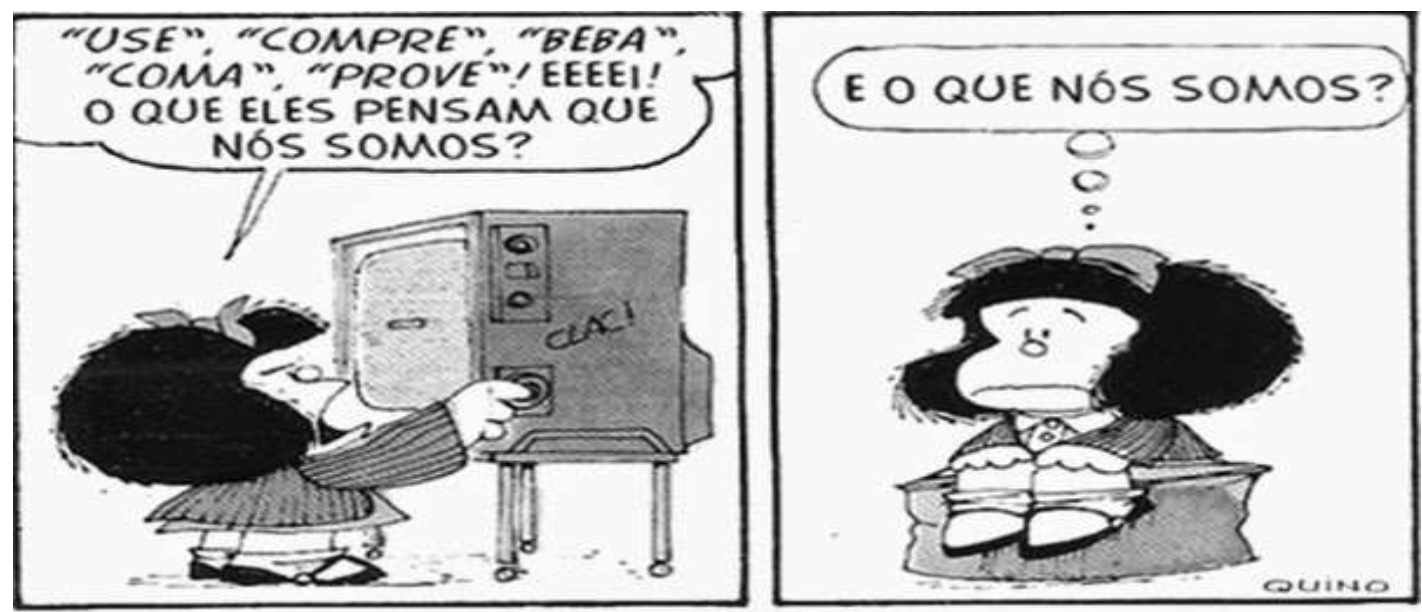

Fonte: Imagem salva do Google Chrome, acesso em 2018. ${ }^{10}$

Podemos refletir a partir da tirinha da figura 09 a respeito de algo que dá sustentação ao sistema capitalista, em que a mídia influencia diretamente na vida das pessoas, estimulando o consumo desenfreado e alienando a sociedade com a falsa ideia que precisamos consumir para nos sentir felizes e satisfeitos. Mafalda nos leva a analisar sobre o que realmente somos e precisamos. Nos mostra que devemos avaliar os informes publicitários e não aderir aos informes apelativos, imperativos e destrutivos que a sociedade capitalista nos impõe.

Figura 10 - Ideologia
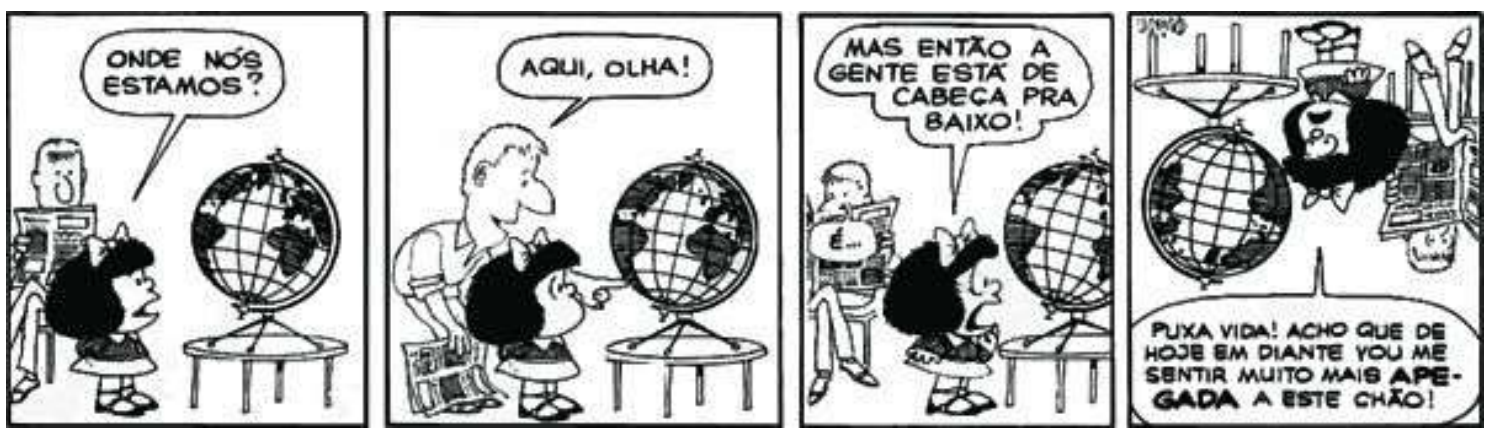

Fonte: Imagem salva do Google Chrome, acesso em 2018. ${ }^{11}$

Na figura 10, Mafalda questiona ao mesmo tempo diversas questões que estão atreladas ao processo de formação do capitalismo mundial, como o nacionalismo, o subdesenvolvimento,

\footnotetext{
${ }^{10}$ Disponível em: <https://fernandonogueiracosta.files.wordpress.com/2017/05/mafalda.jpg? w=700>. Acesso em: 19 mar. 2018.

${ }^{11}$ Disponível em:

<http://portaldoprofessor.mec.gov.br/storage/discovirtual/galerias/imagem/0000000134/0000014856.jpg>. Acesso em: 19 mar. 2018.
} 
a dependência econômica e ideológica, as convenções cartográficas, dentre outros. Percebemos a diversidade e riqueza de informações que podem ser transformadas em conhecimento através da análise de uma tira de quadrinhos. Por meio de questionamentos simples, em uma sequência de quadrinhos, podemos observar uma riqueza de ideias difundidas pelo autor através de uma relação elaborada entre subdesenvolvimento e dependência econômica e cultural.

Partindo das reflexões das tirinhas, tornou-se notável que as histórias em quadrinhos podem ser uma importante ferramenta nas práticas de ensino, pois é um recurso didático que aborda temas geográficos, atuais e de forma descontraída, sendo uma excelente alternativa para potencializar o conteúdo e tornar a aprendizagem mais significativa, e para isso o professor tem a tarefa de trazer as abordagens dos quadrinhos em reflexão com o cotidiano dos alunos.

\section{CONSIDERAÇÕES FINAIS}

A Geografia, por ser uma ciência de paisagens e por despertar a visão interligada entre o homem e seu mundo, é um instrumento que permite nos conhecer e nos compreender melhor, perceber toda a dimensão do espaço e do tempo, onde estamos e para onde caminhamos, descobrir as populações e suas múltiplas relações com o ambiente. A análise realizada nos permitiu compreender que as tiras de quadrinhos e desenhos similares constituem-se de linguagem verbal e não-verbal (imagens) e a sua mensagem apresenta vários sentidos e significados, o que promove o diálogo em suas múltiplas interpretações. Além disso, a sua compreensão depende da contextualização dos fatos, processo que requer um pensamento reflexivo.

A utilização desse recurso didático permite a cada aluno, dentro do seu limite e respeitando seu nível de compreensão, interpretar, analisar e relacionar a importância das muitas linguagens no exame e leitura da paisagem e assim perceber a geografia nas imagens, na literatura, nas notícias e em documentos de diferentes fontes.

A Geografia que se ocupa da análise e da compreensão do espaço geográfico, que por sua vez, é (re)criado a partir das relações humanas sobre a natureza, não deve ser ensinada/aprendida de forma inerte. A pesquisa mostra que a utilização de novas metodologias pode levar os alunos a compreenderem melhor o espaço no qual estão inseridos, a fim de transformar conteúdos em conhecimento, tornando-os mais críticos e conhecedores da realidade que os cercam. Constatamos que as linguagens em quadrinhos utilizadas de forma planejada e 
com objetivos definidos tornam as aulas mais interessantes, divertidas, dinâmicas e, como consequência, os alunos mais participativos e integrados ao processo de ensino- aprendizagem.

As atividades propostas consistem em uma preocupação com a leitura das imagens, que constitui uma das principais habilidades a serem desenvolvidas pela geografia. Assim, ao fazer uma leitura geográfica de uma história em quadrinhos, foram observados os diversos elementos que caracterizam os personagens e as ações, o posicionamento dos objetos e dos personagens, o enquadramento, o ambiente em que se passa a história, que perspectiva ou ângulos são utilizados para retratar o lugar. As histórias em quadrinhos possibilitam, com seu uso, a integração entre as diferentes áreas do conhecimento, desenvolvendo na escola um trabalho interdisciplinar e com diferentes habilidades interpretativas. Os quadrinhos podem ser utilizados em qualquer nível escolar e com qualquer tema.

Através das discussões realizadas nessa pesquisa percebemos que a interligação texto/imagem ocorre nos quadrinhos com uma dinâmica própria e complementar, representa muito mais que o simples acréscimo de uma linguagem. As possibilidades de comunicação são enriquecidas pela familiaridade com as HQS, devido aos variados recursos da linguagem quadrinhística como o balão, a onomatopeia, os diversos planos utilizados pelos desenhistas, que auxiliam no hábito da leitura e enriquecem o vocabulário dos estudantes. As histórias em quadrinhos são escritas em linguagem de fácil entendimento, com muitas expressões que fazem parte do cotidiano dos leitores, ao mesmo tempo, na medida em que tratam de assuntos variados, introduzem sempre palavras novas aos estudantes e o vocabulário vai se ampliando.

Portanto, o caráter elíptico da linguagem quadrinhística obriga o leitor a pensar e imaginar, sendo uma narrativa com linguagem fixa. A constituição de uma história em quadrinhos implica na seleção de momentos chave da história para a utilização expressa na narrativa gráfica, deixando outros momentos a cargo da imaginação do leitor. Podemos constatar a significativa contribuição das tiras em quadrinhos para o processo de ensino e aprendizagem com dinamismo e criticidade.

\section{REFERÊNCIAS}

CALLAI, H. C. Educação geográfica: reflexão e prática. Ijuí: Editora Unijui, 2011.

COELHO, C. S. Parabéns, Mafalda a famosa argentininha faz 50 anos com o mesmo vigor de quando nasceu. Revista conhecimento prático literatura. São Paulo: Editora Escala, 2014, v. 4, n. 4, p. 16-23. 
NEVES. P. D. M.; RUBIRA, F. G. Histórias em quadrinhos na geografia escolar. Revista Geografia, Ensino \& Pesquisa, Vol. 21 (2017), n.3, p. 118-129.

SELBACH, S. Geografia e didática. Rio de Janeiro: Vozes, 2010.

SILVA, E. I. A linguagem dos quadrinhos na mediação do ensino de Geografia: charges e tiras de quadrinhos no estudo de cidade, 2010. Doutorado (Tese), Universidade Federal de Goiás, Programa de Pós-Graduação Em Geografia - Instituto de Estudos Socioambientais. Goiânia, 2010. 213p.

Uso das HQS no ensino. In: RAMA, Â; VERGUEIRO, W (org.). Como usar as histórias em quadrinhos na sala de aula. São Paulo: Contexto, 2015.

RAHDE, M. B. Origens e evolução da história em quadrinhos. Revista Famecos, Porto Alegre. n. 5, novembro 1996, semestral.

RAMA, M. A. G. A representação do espaço nas histórias em quadrinhos do gênero superheróis: a metrópole nas aventuras do Batman. Dissertação (mestrado), Universidade de São Paulo, programa de Pós-Graduação em Geografia Humana, 2006. 131p.

RONDINA, P. C.; TORRES, E. C. Os quadrinhos como ferramenta na construção de um minidicionário de geografia. Caderno Os desafios da escola pública paranaense na perspectiva do professor pde versão online. Paraná, 2014.

SILVA, E. I.; CAVALVANTI, L. A mediação do ensino-aprendizagem de Geografia, por charges, cartuns e tiras de quadrinhos. Boletim Goiano de Geografia, Goiânia, v. 28, n. 2, p. 141-156, jul./dez. 2008. V

VERGUEIRO, W; RAMOS, Paulo (org.). Quadrinhos na educação: da rejeição a prática. 1. ed. São Paulo: Contexto, 2015. 